\title{
Photocatalytic Activities of Vertically Aligned Manganese- Doped ZnO Nanorods Synthesized on ITO Film by Electrochemical Technique
}

\author{
Liqun Fan, Jinhu Wang, Na Qiu, Yong Liu*, Xianman Zhang \\ College of Chemistry, Chemical Engineering and Materials Science, Zaozhuang University, \\ Zaozhuang, shandong 277160, China \\ *E-mail: liuyong20049@163.com
}

doi: $10.20964 / 2019.12 .09$

Received: 6 June 2019 / Accepted: 5 August 2019 / Published: 29 October 2019

\begin{abstract}
A facile electrochemical approach was used to one step growth of $\mathrm{Mn}$-doped $\mathrm{ZnO}$ nanorods on indium tin oxide conductive glass. FESEM images show an increase in diameter and height of $\mathrm{ZnO}$ nanorods by doping $\mathrm{Mn}$ ions in $\mathrm{ZnO}$ lattice. XRD results indicate that the Mn dopant lead to a shift in the diffraction peak position toward a lower angle side compared to the undoped $\mathrm{ZnO}$ nanorods. Electrochemical impedance spectroscopy results proving that doping $\mathrm{Mn}$ ions in $\mathrm{ZnO}$ nanorods can lead to higher free-electron carriers that accelerate charge transfer and reduces the resistance. Photocatalytic activities of the sample were studied by degrading methylene blue under UV-vis light irradiation. The photodegradation efficiency of $\mathrm{Mn}$-doped $\mathrm{ZnO}$ nanorods achieved for $100 \mathrm{~min}$ irradiation times was $81 \%$ which reveals better findings compared to previous reports. The $\mathrm{Mn}$-doped $\mathrm{ZnO}$ nanostructures have higher rate constant and degradation efficiency as it has higher surface defects, length, and crystallinity than others.
\end{abstract}

Keywords: Mn-doped $\mathrm{ZnO}$ nanorods; Photocatalytic activities; Electrochemical impedance spectroscopy; Electrochemical technique

\section{FULL TEXT}

(C) 2019 The Authors. Published by ESG (www.electrochemsci.org). This article is an open access article distributed under the terms and conditions of the Creative Commons Attribution license (http://creativecommons.org/licenses/by/4.0/). 